\title{
SIMULASI PELIMPAHAN BEBAN SISTEM PMT KOPEL TO KOPEL PADA SAAT PEMELIHARAAN TRAFO BERBASIS ARDUINO MEGA 2560 MENGGUNAKAN VT SCADA 11.2
}

\author{
Mochammad Rizki Samputro, Arkhan Subari \\ Program Studi Diploma III Teknik Elektro, \\ Sekolah Vokasi, Universitas Diponegoro \\ Jl. Prof. Soedarto, SH, Kampus Undip Tembalang, Semarang, Indonesia 50275
}

\begin{abstract}
Mochammad Rizki Samputro, Arkhan Subari in this paper explains that the need for electricity in everyday life demands PT. PLN to always maintain the distribution of electrical energy to customers. Therefore, it is necessary to use a strategy to prevent blackouts if the transformer is being maintained, that is by maneuvering the load through the network or by using a $20 \mathrm{KV}$ coupling system. The $20 \mathrm{KV}$ Coupling System consists of PMT Kopel Transformer 1 and PMT Kopel Transformer 2 or often called PMT Kopel to Kopel. In this research, a Kopel to Kopel PMT simulation tool is used to transfer transformer loads during maintenance using a LY2N DPDT 12 $V$ relay, ZMCT103C current transformer sensor, voltage sensor, tap changer and use Arduino Mega 2560 as a delivery choice change. After the experiment, the total current size of transformer 1 and transformer 2 exceeds the capacity of transformer which is $4.29 \mathrm{~A}$ and the voltage difference is $0.71 \mathrm{~V}(5.9 \%)$. Therefore it is necessary to adjust the current and voltage regulation so that it becomes $2.82 \mathrm{~A}$ and $0.06 \mathrm{~V}(0.5 \%)$. After that the transfer of load Transformer 2 to Transformer 1 using PMT Kopel to Kopel can be done. The load transfer is done by entering the PMT Kopel 1 and PMT Kopel 2 simultaneously and the Incoming 2 PMT is released. For the normalization, PMT Incoming 2 is entered and PMT Kopel 1 and Kopel 2 are released simultaneously.
\end{abstract}

Keywords: Coupling; Load Transfer; Normalization; Kopel to Kopel; Arduino; VTScada;

\section{PENDAHULUAN}

Gardu Induk Distribusi adalah gardu listrik yang mendapatkan daya dari saluran distribusi primer yang menyalurkan tenaga listrik ke pemakai dengan tegangan rendah[1]. Gardu Induk Disribusi merupakan instalasi sistem penyaluran tenaga listrik dengan tegangan menengah $(20 \mathrm{KV})$ ke pusat - pusat beban. Di dalamnya terdapat kubikel / panel bagi yaitu Incoming, Outgoing, Kopel, Pengukuran dan Trafo Pemakaian Sendiri. Kubikel Incoming disuplai dari output Trafo Tenaga (sisi Sekunder). Kubikel Incoming merupakan Induk dari Outgoing. Kubikel Kopel berfungsi untuk memaralel / menghubungkan dua busbar sel kubikel trafo yang berbeda[2]. Kubikel Outgoing yang berfungsi menghubung dan memutus sumber ke gardu distribusi / pelanggan.

Demi menjaga kontinuitas penyaluran energi listrik maka perlu adanya strategi yang digunakan agar tidak terjadi pemadaman apabila dilakukan pemeliharaan yang terdapat pada trafo $150 / 20 \mathrm{KV}$ dan perlengkapannya. Ada dua cara untuk menjaga kontinuitas penyaluran energi listrik pada saat akan ada pemeliharaan pada trafo yaitu dengan cara manuver di jaringan atau dengan melakukan pengalihan beban dengan menggunakan Sistem Kopel.

Manuver jaringan adalah pekerjaan pengalihan/pelimpahan beban baik sebagian maupun seluruh penyulang ke penyulang lain yang bersifat sementara. Dalam manuver jaringan, kegiatan yang dilakukan yaitu menghubungkan bagian-bagian jaringan yang terpisah menurut keadaan operasi normalnya dan memisahkan jaringan menjadi bagianbagian jaringan yang semula terhubung menurut keadaan operasi normalnya[3].

Sedangkan Sistem Kopel $20 \mathrm{KV}$ diperlukan untuk back up maupun menghemat waktu terkait pelimpahan beban kedua trafo pada saat dilaksanakan pemeliharaan yang tidak memerlukan penyulang untuk padam. Penggunaan kubikel kopel ini berfungsi untuk menghubungkan antar kubikel yang berada pada trafo (sel) yang berbeda. Oleh karena itu, pelimpahan beban dengan Sistem Kopel dapat sangat dibutuhkan ketika adanya pemeliharaan trafo[4].

Pada penelitian sebelumnya, proses pelimbahan beban menggunakan sistem Kopel to Interface[2] yang bisa menyebabkan blackout apabila kapasistas trafo yang dituju tidak mencukupi saat pelimpahan terjadi. Selain itu pemeliharaan trafo pada sistem Kopel to Interface dilakukan secara hatihati. Pada sistem ini, trafo tidak sepenuhnya terlepas dari jaringan dan beban, sehingga cukup berbahaya. Hal tersebut dapat diatasi dengan sistem Kopel to Kopel. Pada sistem Kopel to Kopel persyaratan nilai arus dan tegangan harus dipenuhi, sehingga tidak terjadi blackout. Selain itu pada sistem ini, ketika terjadi pemeliharaan trafo, dapat dipastikan bahwa trafo terlepas dari jaringan dan beban, sehingga proses pemeliharaan dapat dilakukan dengan lebih aman. Penggunaan sistem Kopel to Kopel sesuai dengan SOP PT. PLN yang terbaru, yang terdiri dari 2 PMT Kopel sebagai saklar yang menghubungkan kedua buah busbar Trafo 1 dan Trafo 2 atau sering disebut PMT Kopel to Kopel. Dalam pelimpahan 
beban dari Trafo 1 ke Trafo 2 harus memenuhi beberapa persyaratan seperti besar tegangan harus sama maksimal beda tegangan $0,5 \mathrm{kV}(2,5 \%)$ dan jumlah beban kedua trafo tidak boleh melebihi kapasitas trafo[5], sehingga tidak akan terjadi blackout saat pelimpahan. Tujuan penelitian ini adalah untuk mensimulasikan proses pelimpahan beban menggunakan sistem Kopel to Kopel sesuai dengan SOP dari PT. PLN sehingga tidak terjadi blackout pada saat pelimpahan beban dilakukan.

Untuk itu diperlukan monitoring beban dan tegangan secara langsung melalui power meter pada kubikel PMT Kopel di Gardu Induk dan secara jarak jauh melalui VT SCADA yang terletak di ruang dispatcher Unit Pelaksana Pengaturan Distribusi (UP2D) PT. PLN (Persero). Dengan adanya VTScada ini sangat membantu untuk menampilkan arus dan tegangan di layar HMI dengan demikian dapat diketahui besaran arus dan tegangan melalui VTScada[6].

\section{METODE PENELITIAN}

Dalam perencanaan alat simulasi, konfigurasi jaringan yang akan dibuat yaitu meliputi 2 sumber trafo dengan kapasitas 5 A, 2 PMT Incoming, 2 PMT Kopel, 2 penyulang pada Trafo 1 dan 1 penyulang pada Trafo 2. Gambar single line diagram ditunjukkan pada Gambar 1.

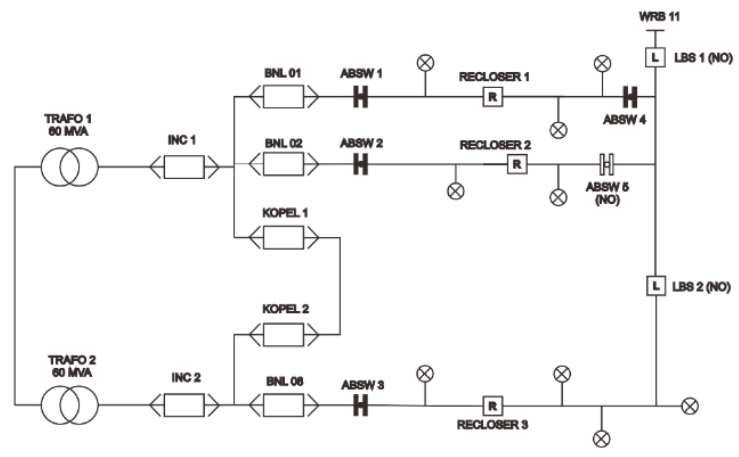

Gambar 1. Single Line Diagram Alat Simulasi

Komponen dan peralatan yang digunakan pada alat simulasi ini berfungsi sebagai pengganti peralatan sistem pada peralatan Gardu Induk $20 \mathrm{KV}$ yang sebenarnya. Trafo digantikan dengan catu daya 12 VAC, Tap changer Trafo $20 \mathrm{KV}$ diganti dengan Rotary Switch, peralatan PMT dan LBS akan diganti dengan relay LY2N DPDT, ABSw diganti dengan saklar ON/OFF, PT (Potential Transfromator) diganti dengan sensor tegangan, CT (Current Transformator) diganti dengan trafo arus ZMCT103C, dan PLC diganti dengan Arduino Mega 2560. Pemilihan penggunaan Arduino didasari fakta bahwa Arduino merupakan modul yang dibuat dengan dasar rangkain mikrokontroler (bagian dari sistem mikrokomputer[12]) yang dirancang sedemikian rupa sehingga fleksibel dan mudah digunakan[10]. Untuk pengoperasian Relay akan dihubungkan dengan rangkaian pulldown sebagai input (trigger) tegangan Arduino Mega 2560[7,8].
Beban yang dipakai adalah lampu $5 \mathrm{~W} 12 \mathrm{VAC}, 3$ lampu pada penyulang BNL 01, 2 lampu pada penyulang BNL 02, dan 4 lampu pada penyulang BNL 08. Gambar rangkaian keseluruhan alat ditunjukkan pada Gambar 2.

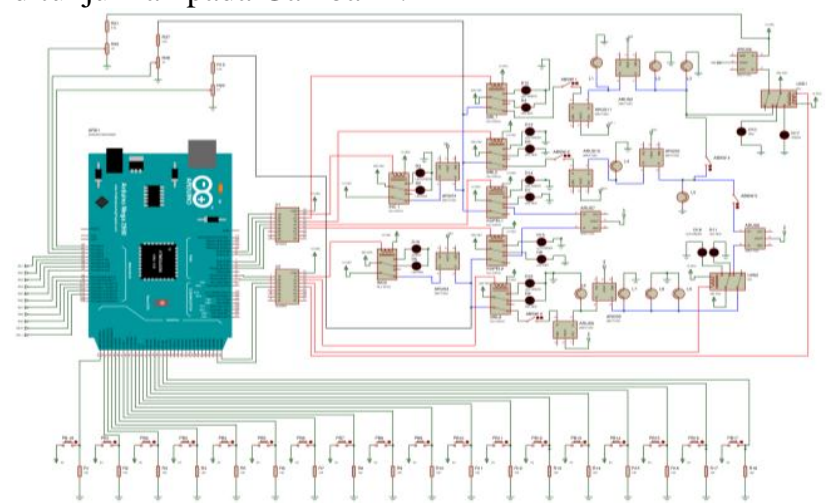

Gambar 2. Rangkaian Keseluruhan Alat Simulasi

Pemeliharaan trafo disimulasikan dengan mematikan sumber Trafo 2. Kriteria yang harus dipenuhi dalam sistem kopel alat simulasi ini diasumsikan sudah terpenuhi. Sedangkan dalam pelimpahan beban menggunakan PMT Kopel to Kopel harus memenuhi persyaratan pelimpahan beban terlebih dahulu. Persyaratannya yaitu besar teganan kedua trafo sama (maksimal beda tegangan $0,5 \mathrm{KV}$ atau 2,5\%) [5]. Dan total arus beban tidak melebihi $85 \%$ dari kapasitas satu trafo [9]. Apabila tegangan belum sama, maka dapat disamakan terlebih dahulu dengan tap changer/ tuas trafo. Dan apabila total arus beban melebihi $85 \%$ dari kapasitas trafo maka dapat dilakukan pelimpahan beban melalui manuver jaringan untuk mengurangi total arus beban.

Sistem penyesuaian arus bertujuan untuk mengatur arus beban total pada Trafo 1 dan Trafo 2 pada kondisi arus beban melebihi atau mendekati kapasitas Trafo 1 dengan toleransi $85 \%$ dari 5 A yaitu 4,25 A. Penyesuaian arus beban dilakukan dengan cara melepas penyulang BNL 01 dan dilimpahkan ke penyulang WRB 11 melalui LBS. Gambar rangkaian penyesuaian arus ditunjukkan pada Gambar 3 .

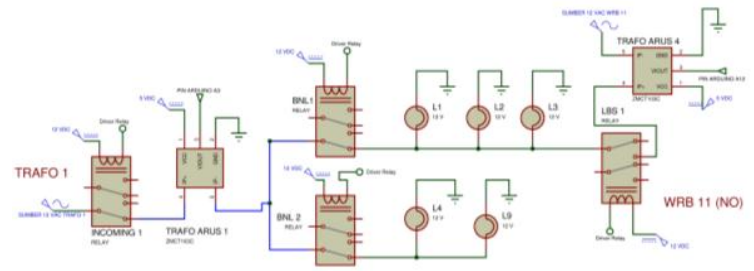

Gambar 3. Rangakaian Penyesuaian Arus

Diagram alir dari rangkaian penyesuaian arus ditunjukkan pada Gambar 4.

Sistem pengaturan tegangan bertujuan untuk mengatur tegangan pada Trafo 1 dan Trafo 2 pada saat kondisi selsisih tegangan melebihi toleransi 2,5\% dari $12 \mathrm{~V}$ yaitu $0.3 \mathrm{~V}$. Pengaturan tegangan dilakukan dengan cara memutar tuas Rotary Switch sebagai pengganti tap changer yang berfungsi sebagai 
penstabil tegangan[11]. Gambar rangkaian pengaturan tegangan ditunjukkan pada Gambar 5.

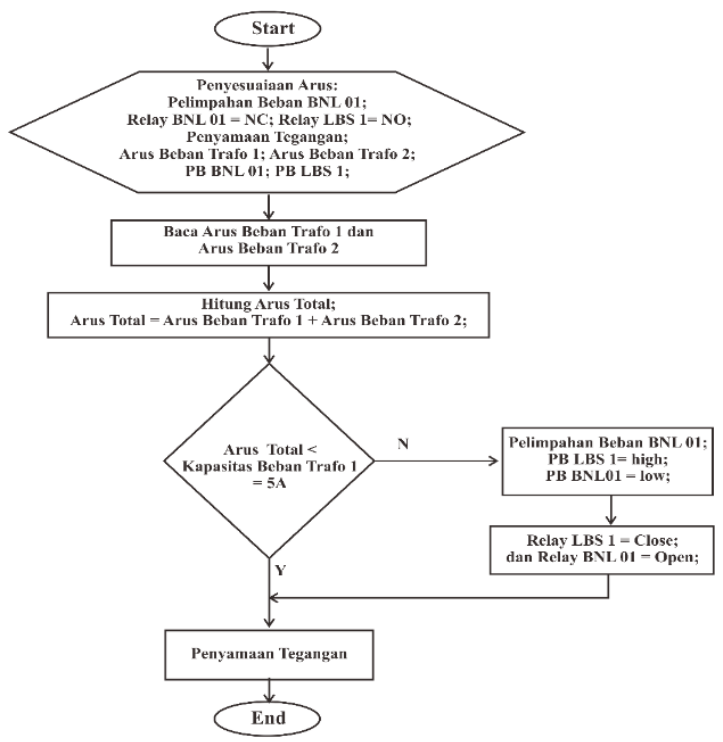

Gambar 4. Diagram Alir Penyesuaian Arus

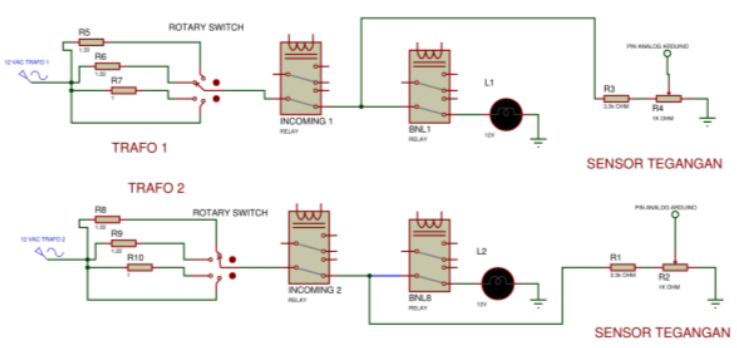

Gambar 5. Rangkaian Pengaturan Tegangan

Diagram alir dari rangkaian pengaturan tegangan ditunjukkan pada Gambar 6.

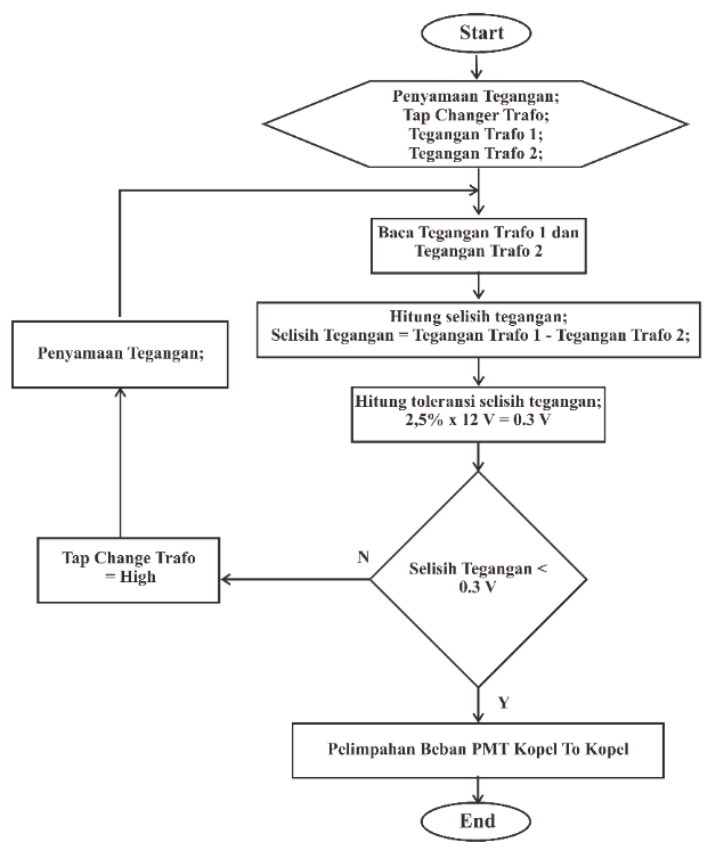

Gambar 6. Diagram Alir Pengaturan Tegangan
Sistem pelimpahan beban dengan PMT Kopel to Kopel merupakan inti pembahasan dari alat ini. Sistem pelimpahan beban dengan PMT Kopel bertujuan untuk melimpahkan beban dari Trafo 2 ke Trafo 1 ketika Trafo 2 dalam pemeliharaan. Gambar rangkaian pelimpahan beban dengan PMT Kopel to Kopel ditunjukkan pada Gambar 7.

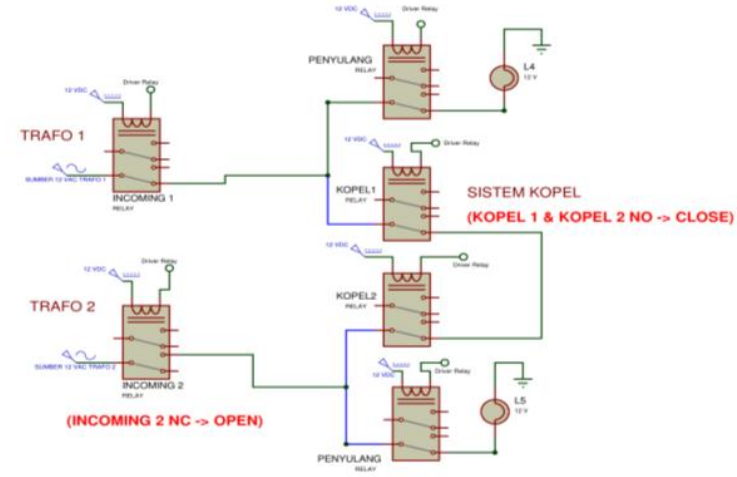

Gambar 7. Rangkaian Pelimpahan Beban

Diagram alir dari rangkaian pelimpahan beban ditunjukkan pada Gambar 8.

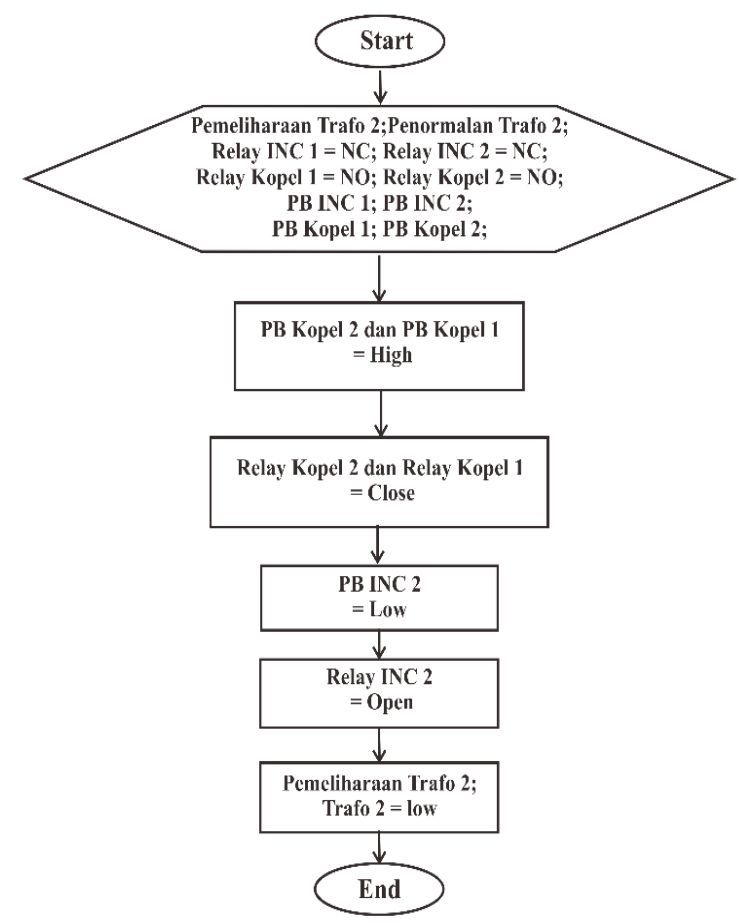

Gambar 8. Diagram Alir Pelimpahan Beban

Sistem penormalan beban merupakan tahap selanjutnya apabila telah dilaksanakan proses pelimpahan beban Trafo 2 ke Trafo 1 melalui PMT Kopel to Kopel. Penormalan beban bertujuan untuk mengembalikan jaringan Trafo 1 dan Trafo 2 pada kondisi semula ketika pemeliharaan sudah selesai. Gambar rangkaian penormalan beban dengan PMT Kopel to Kopel ditunjukkan pada Gambar 9sedangkan diagram alir dari rangkaian pelimpahan beban ditunjukkan pada Gambar 10. 


\section{HASIL DAN PEMBAHASAN}

Pengujian dilakukan dengan menghubungkan seluruh perangkat beserta isinya, baik itu hardware dan software. Tujuan dari percobaan alat secara keseluruhan adalah untuk mengetahui apakah kerja dari simulasi alat penelitian ini sudah dapat berfungsi dan sesuai dengan yang direncanakan, dimana dapat melakukan Simulasi PMT Kopel To Kopel pada pelimpahan beban saat pemeliharaan trafo berbasis Arduino Mega 2560 dan dapat dimonitori dengan menggunakan VT SCADA.

Pengujian alat diawali dengan penyesuaian arus yang dilakukan apabila total arus Trafo 1 dan Trafo 2 melebihi kapasitas Trafo 1 yaitu lebih dari 4,25 Aditunjukkan pada tabel 1.

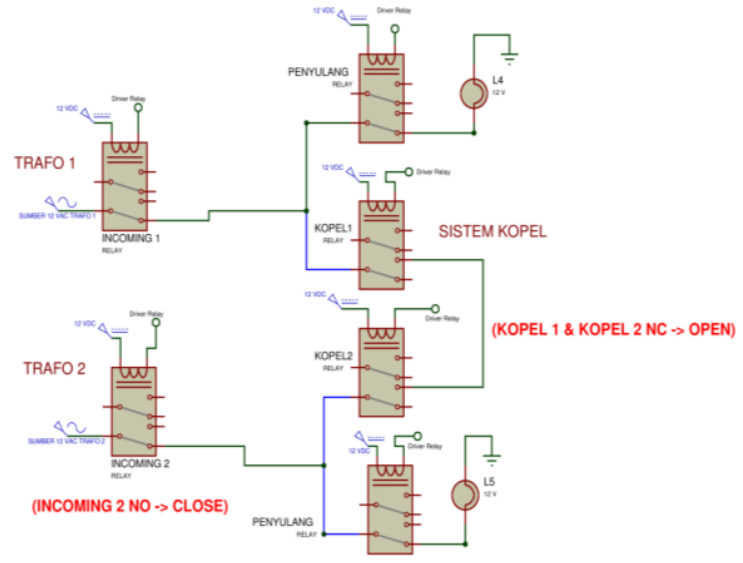

Gambar 9. Rangkaian Penormalan Beban

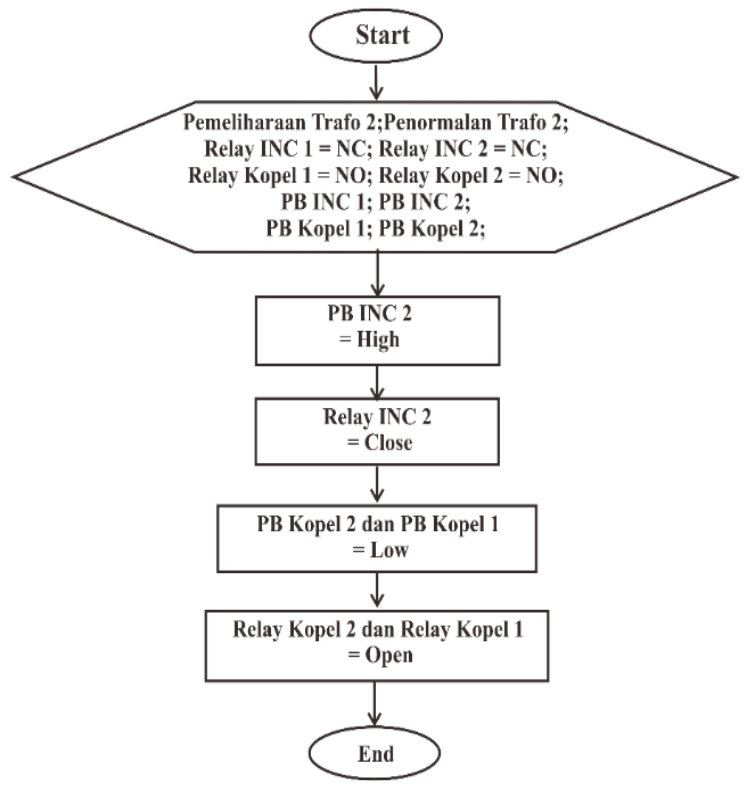

Gambar 10. Diagram Alir Penormalan Beban

Tabel 1. Arus Total Trafo 1 dan Trafo 2

\begin{tabular}{ccc}
\hline No & Titik Ukur & Pengukuran \\
\hline 1 & Incoming 1 & $2,38 \mathrm{~A}$ \\
2 & Incoming 2 & $1,92 \mathrm{~A}$ \\
3 & Total & $4,29 \mathrm{~A}$ \\
\hline
\end{tabular}

Berdasarkan pada tabel 1, besar total arus melebihi dari persyaratan yaitu sebesar 4,29A. Oleh karenanya perlu disesuaikan agar tidak menyebabkan trip pada PMT yang bisa berakibat terjadinya blackout. Penyesuaian arus beban dilakukan dengan cara melepas penyulang BNL 01 dan dilimpahkan ke penyulang WRB 11 melalui LBS. Hasil penyesuaian arus ditunjukkan pada tabel 2.

Tabel 2. Hasil Penyesuaian Arus

\begin{tabular}{ccc}
\hline No & Titik Ukur & Pengukuran \\
\hline 1 & Incoming 1 & $0,89 \mathrm{~A}$ \\
2 & Incoming 2 & $1,92 \mathrm{~A}$ \\
3 & Total & $4,29 \mathrm{~A}$ \\
\hline
\end{tabular}

Setelah penyesuaian arus telah berhasil, maka syarat kedua yang harus dipenuhi yaitu besar tegangan harus sama (toleransi 2,5\% dari $12 \mathrm{~V}$ yaitu sebesar 0,3V). Besar tegangan pada Trafo 1 dan Trafo 2 kondisi normal ditunjukkan pada tabel 3 .

Tabel 3. Besar Tegangan Trafo 1 dan Trafo 2

\begin{tabular}{ccc}
\hline No & Titik Ukur & Pengukuran \\
\hline 1 & Trafo 1 & $9,75 \mathrm{~V}$ \\
2 & Trafo 2 & $10,46 \mathrm{~V}$ \\
3 & Selisih & $0,71 \mathrm{~V}$ \\
\hline
\end{tabular}

Dikarenakan terdapat selisih tegangan yang melebihi toleransi yaitu sebesar 0,71 V. Maka perlu adanya pengaturan tegangan dengan memutar tuas tap changer. Hasil pengaturan tegangan ditunjukkan pada tabel 4 .

Tabel 4. Hasil Pengaturan Tegangan

\begin{tabular}{ccc}
\hline No & Titik Ukur & Pengukuran \\
\hline 1 & Trafo 1 & $9,80 \mathrm{~V}$ \\
2 & Trafo 2 & $9,86 \mathrm{~V}$ \\
3 & Selisih & $0,06 \mathrm{~V}$ \\
\hline
\end{tabular}

Apabila penyesuaian arus dan pengaturan tegangan telah selesai, maka proses pelimpahan beban dengan menggunakan PMT Kopel to Kopel dapat dilaksanakan. Pelimpahan beban dilakukan dengan cara menekan push button close $(\mathrm{ON})$ pada PMT Kopel 1 dan Kopel 2 secara bersamaan dan selanjutnya menekan push button open (OFF) pada PMT Incoming [13]. Pada kondisi ini, trafo yang akan dipelihara benar-benar terlepas dari jaringan dan beban. Dengan demikian proses pemeliharaan trafo dapat dilkaukan dengan lebih aman, karena tidak adanya arus yang mengalir pada trafo tersebut. Hasil pengujian pelimpahan beban dengan menggunakan PMT Kopel to Kopel ditunjukkan pada tabel 5. 
Tabel 5. Pelimpahan Beban Trafo 1 dan Trafo 2

\begin{tabular}{cccc}
\hline No & PMT & Kondisi & Pengukuran \\
\hline 1 & Incoming 1 & NC & $0,88 \mathrm{~A}$ \\
2 & Incoming 2 & NC & $1,89 \mathrm{~A}$ \\
3 & Kopel 1 & NO & $0,00 \mathrm{~A}$ \\
4 & Kopel 2 & NO & $0,00 \mathrm{~A}$ \\
5 & Incoming 1 & Close & $2,59 \mathrm{~A}$ \\
6 & Incoming 2 & Open & $0,00 \mathrm{~A}$ \\
7 & Kopel 1 & Close & $1,81 \mathrm{~A}$ \\
8 & Kopel 2 & Close & $1,81 \mathrm{~A}$ \\
\hline
\end{tabular}

Sedangkan hasil pengujian penormalan beban dengan menggunakan PMT Kopel to Kopel ditunjukkan pada tabel 6 .

Tabel 6. Penormalan Beban Trafo 1 dan Trafo 2

\begin{tabular}{cccc}
\hline No & PMT & Kondisi & Pengukuran \\
\hline 1 & Incoming 1 & NC & $2,59 \mathrm{~A}$ \\
2 & Incoming 2 & NO & $0,00 \mathrm{~A}$ \\
3 & Kopel 1 & NC & $1,81 \mathrm{~A}$ \\
4 & Kopel 2 & NC & $1,81 \mathrm{~A}$ \\
5 & Incoming 1 & Close & $0,88 \mathrm{~A}$ \\
6 & Incoming 2 & Close & $1,91 \mathrm{~A}$ \\
7 & Kopel 1 & Open & $0,00 \mathrm{~A}$ \\
8 & Kopel 2 & Open & $0,00 \mathrm{~A}$ \\
\hline
\end{tabular}

Apabila penormalan beban dengan menggunakan PMT Kopel to Kopel telah selesai, maka langkah selanjutnya yaitu menormalkan jaringan seperti semula dengan memasukkan BNL 01 dan melepas WRB 11. Hasil penormalan jaringan ditunjukkan pada tabel 7 .

Tabel 7. Hasil Penormalan Jaringan

\begin{tabular}{cccc}
\hline No & PMT & Kondisi & Pengukuran \\
\hline 1 & Incoming 1 & $N C$ & $2,38 \mathrm{~A}$ \\
2 & Incoming 2 & $N O$ & $1,91 \mathrm{~A}$ \\
3 & BNL 01 & $N C$ & $1,45 \mathrm{~A}$ \\
4 & WRB 11 & $N C$ & $1,02 \mathrm{~A}$ \\
\hline
\end{tabular}

\section{KESIMPULAN}

Peyesuaian arus perlu dilakukan karena total arus Trafo 1 dan Trafo 2 lebih dari kapasitas Trafo 1 yaitu sebesar 4,25 A. Proses penyesuaian arus dilakukan dengan melimpahkan penyulang BNL 01 ke WRB 11 sehingga arus total yang semula 4,29 A menjadi 2,82 A.

Pengaturan tegangan dilakukan apabila terdapat selisih tegangan Trafo 1 dan Trafo 2 lebih dari 0,3 V. Pengaturan tegangan dilakukan dengan cara mengubah posisi tap changer sehingga selisih tegangan yang semula $0,71 \mathrm{~V}$ menjadi $0,06 \mathrm{~V}$.

Apabila arus dan tegangan sudah sesuai persyaratan, maka proses pelimpahan beban dengan PMT Kopel to Kopel dapat dilakukan dengan memasukkan PMT Kopel 1 dan PMT Kopel 2 secara bersamaan dan kemudian melepas PMT Incoming 2. Setelah itu besar arus pada Trafo1 menjadi 2,62 A dan arus pada Kopel sebesar 1,835 A.
Dari hasil pengujian didapatkan bahwa simulasi berhasil dijalankan untuk melakukan pelimpahan beban dengan sistem Kopel to Kopel dengan menjaga beban tetap berada pada kondisi yang disyaratkan sehingga tidak terjadi blackout.

\section{UCAPAN TERIMA KASIH}

Terimakasih kepada Sekolah Vokasi Universitas Diponegoro dan PT. PLN DCC Yogyakarta yang sangat banyak membantu pengumpulan data dan terlaksananya penelitian ini.

\section{DAFTAR PUSTAKA}

1. Mustaghfirin Amin, dkk. 2013. Buku Gardu Induk. Jakarta: Departemen Pendidikan dan Kebudayaan

2. B. Wibowo, and S. Manan, 2014, Pemanfaatan PMT Kopel Sebagai Sarana Pengalihan Beban Di Gardu Induk Sayung Kabupaten Demak, Gema Teknologi, vol. 18, no. 1, pp. 915, Oct. 2014. https://doi.org/10.14710/gt.v18i1.8809

3. Alvin, Akbar. 2012 . Manuver Jaringan Distribusi. Laporan On Job Training (OJT). Semarang: PT PLN (Persero) Distribusi Jawa Tengah Dan DIY Rayon Semarang Selatan.

4. Nur, Anisa. 2018. Penggunaan Interface Dan Bus Riser Pada Kubikel 20kv Di Gardu Induk 150kv Krapyak. Laporan Kerja Praktek (tidak diterbitkan). Yogyakarta: Universitas Gajah Mada.

5. PT PLN (Persero). 2016. Standing Operation Procedure (SOP) Manuver Jaringan PLN. Jakarta : PT. PLN (Persero)

6. Abdillah, Syehan. 2017. Prototype Indikator Penurunan Arus Hubung Singkat Satu Fasa Ketanah Pada Ground Fault Relay Menggunakan Human Machine Interface Berbasis Arduino Mega 2560. Laporan Penelitian (tidak diterbitkan). Semarang: Universitas Diponegoro.

7. Nugroho, Galang Adi. 2018. Simulasi Panel RTU dengan Sistem Interlock Pada Panel Outgoing 20 KV Dilengkapi dengan IED Digital Power Meter ION 6200 Berbasis Arduino Mega 2560. Laporan Penelitian (tidak diterbitkan). Semarang: Universitas Diponegoro.

8. D. Ashifa, and A. Subari, 2019, Simulasi Penentuan Lokasi Gangguan Satu Fasa Pada Jaringan Tegangan Menengah 20 KV Berbasis Arduino Mega 2560 Dilengkapi Dengan Monitoring Melalui VTScada, Gema Teknologi, vol. 20, no. 2, pp. 54-59, Apr. 2019. https://doi.org/10.14710/gt.v20i2.23097.

9. K. Bawan, Elias. 2013. Estimasi Pembebanan Transformator Gardu Induk 150 KV. Jurnal Ilmiah Faristek Vol.3, No.2. Universitas Negeri Papua: Manokwari. 
10. G. Wohingati, and A. Subari, 2015, Alat Pengukur Detak Jantung Menggunakan Pulsesensor Berbasis Arduino Uno R3 Yang Diintegrasikan Dengan Bluetooth, Gema Teknologi, vol. 17, no. 2, Aug. 2015. https://doi.org/10.14710/gt.v17i2.8919

11. Firdha, Maula. 2016. Penstabilan Tegangan Sekunder Pada Transformator Daya 150/20 KV Akibat Jatuh Tegangan (skripsi). Semarang: Universitas Semarang.

12. R. Dewi, and A. Subari, 2012, Rancang Bangun Aplikasi Pengukuran Tinggi Badan, Berat Badan, Suhu Tubuh, Dan Tekanan
Darah Berbasis Miktrokontroler ATMEGA16, Gema Teknologi, vol. 17, no. 1, pp. 43-52, Oct. 2012. https://doi.org/10.14710/gt.v17i1.8916

13. Akhdan, Abu. 2013. Tombol Tekan (Push Button) Jenis Serta Fungsinya. https://akhdanazizan.com/. (Diakses 27 Juni 2019). 